\title{
Triflumizole as a Novel Lead Compound for Strigolactone Biosynthesis Inhibitor
}

\author{
Kojiro Kawada ${ }^{1}$, Yuya Uchida ${ }^{1}$, Ikuo Takahashi ${ }^{2}$, Takahito Nomura ${ }^{3}$, Yasuyuki Sasaki ${ }^{1}$, \\ Tadao Asami ${ }^{2}$, Shunsuke Yajima ${ }^{1}(1)$ and Shinsaku Ito ${ }^{1, *}$ \\ 1 Department of Bioscience, Tokyo University of Agriculture, Setagaya, Tokyo 156-8502, Japan; \\ kawa7440@gmail.com (K.K.); uhi-yu1998@ezweb.ne.jp (Y.U.); y1sasaki@nodai.ac.jp (Y.S.); \\ yshun@nodai.ac.jp (S.Y.) \\ 2 Graduate School of Agricultural and Life Sciences, The University of Tokyo, Bunkyo, Tokyo 113-8657, Japan; \\ takahashi.190@gmail.com (I.T.); asami@g.ecc.u-tokyo.ac.jp (T.A.) \\ 3 Center for Bioscience Research and Education, Utsunomiya University, Utsunomiya, Tochigi 321-8505, Japan; \\ tnomura@cc.utsunomiya-u.ac.jp \\ * Correspondence: s4ito@nodai.ac.jp; Tel.: +81-3-5477-2460
}

Academic Editors: Wilfried Rozhon and Marcello Iriti

Received: 16 September 2020; Accepted: 23 November 2020; Published: 25 November 2020

\begin{abstract}
Strigolactones (SLs) are carotenoid-derived plant hormones involved in the development of various plants. SLs also stimulate seed germination of the root parasitic plants, Striga spp. and Orobanche spp., which reduce crop yield. Therefore, regulating SL biosynthesis may lessen the damage of root parasitic plants. Biosynthetic inhibitors effectively control biological processes by targeted regulation of biologically active compounds. In addition, biosynthetic inhibitors regulate endogenous levels in developmental stage- and tissue-specific manners. To date, although some chemicals have been found as SL biosynthesis inhibitor, these are derived from only three lead chemicals. In this study, to find a novel lead chemical for SL biosynthesis inhibitor, 27 nitrogen-containing heterocyclic derivatives were screened for inhibition of SL biosynthesis. Triflumizole most effectively reduced the levels of rice SL, 4-deoxyorobanchol (4DO), in root exudates. In addition, triflumizole inhibited endogenous $4 \mathrm{DO}$ biosynthesis in rice roots by inhibiting the enzymatic activity of Os900, a rice enzyme that converts the SL intermediate carlactone to 4DO. A Striga germination assay revealed that triflumizole-treated rice displayed a reduced level of germination stimulation for Striga. These results identify triflumizole as a novel lead compound for inhibition of SL biosynthesis.
\end{abstract}

Keywords: strigolactone; P450 inhibitor; screening; triflumizole; rice

\section{Introduction}

Strigolactones (SLs) are a group of terpenoid lactones derived from carotenoids. More than 20 SLs, including 4-deoxyorobanchol (4DO), orobanchol, and methyl carlactonoate (MeCLA), have been reported from various plant species [1]. SLs function as plant hormones that regulate several important developmental processes in plants, including the regulation of shoot branching and stress tolerance [2-4]. In addition, SLs are allelochemicals that induce branching of hyphae in arbuscular mycorrhizal fungi and germination in root parasitic plants $[5,6]$.

Root parasitic plants, such as Orobanche spp. and Striga spp., are harmful for crop production in Sub-Saharan Africa, the Middle East, and Asia [7]. In the savanna regions of Africa alone, annual losses amount to \$US 7 billion [8]. Host plant mutants deficient in SL biosynthesis prevent infection by root parasitic plants. Thus, it is possible that inhibition of SL biosynthesis could reduce these damages [3]. 
Inhibitors of the biosynthesis of bioactive substances are useful to regulate biosynthetic pathways. While loss-of-function mutants in a biosynthetic pathway may result in a lethal phenotype, biosynthesis inhibitors can control the endogenous levels of metabolites in a developmental stage- and tissue-specific manner [9]. In addition, although gene knockout in multiple paralogous genes rarely produces a clear phenotype, biosynthetic inhibitors can overcome such gene redundancy in many cases. Therefore, the use of biosynthetic inhibitors is a valuable way to evaluate the physiological roles of endogenous substances.

Genetic analysis using a series of branching mutants has revealed several enzymes involved in SL biosynthesis. In the first step, all-trans- $\beta$-carotene is converted to 9 -cis- $\beta$-carotene by the D27 carotenoid isomerase [10]. Carlactone (CL), which is synthesized from 9-cis- $\beta$-carotene by two carotenoid cleavage dioxygenases, CCD7 (AtMAX3 in Arabidopsis/D17 in rice) and CCD8 (AtMAX4 in Arabidopsis/D10 in rice), is an important precursor of SLs $[10,11]$. In rice, cytochrome P450 proteins (CYPs) catalyze the conversion of CL to SLs. Os900 (CYP711A2) oxidizes CL to 4DO via carlactonoic acid (CLA). 4DO is converted to orobanchol by Os1400 (CYP711A3). Os1400 also catalyzes the conversion of CL to CLA (Figure 1). In Arabidopsis, AtMAX1 (CYP711A1) only shows catalytic activity from CL to CLA [12,13].

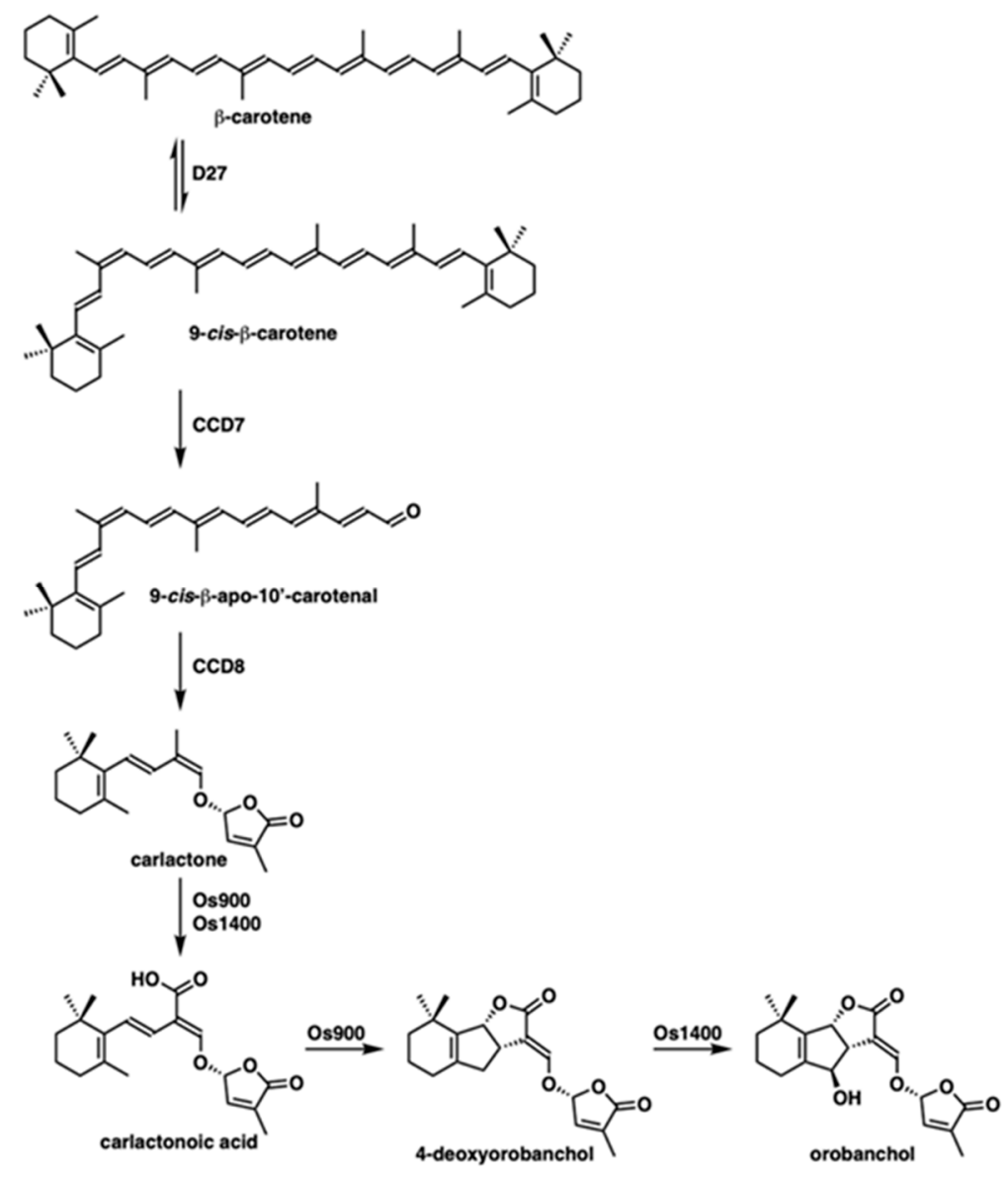

Figure 1. Strigolactone biosynthesis pathway in rice.

It has been reported that nitrogen-containing heterocyclic compounds, including imidazole and triazole groups, have inhibitory activities against various CYPs in mammals, microorganisms, and plants [14-18]. Thus, these compounds are good candidates as SL biosynthesis inhibitors. In our previous study, we screened for chemicals that induce second tiller bud outgrowth in rice, which is characteristic of SL-deficient mutants. The triazole-containing compound TIS13 was identified as the lead compound for SL biosynthesis inhibitors [19]. A structure-activity relationship study based on the structure of TIS13 identified two potent and specific SL biosynthesis inhibitors, TIS108 and 
KK5 [20,21]. In addition to TIS13, of seven azole derivatives identified as fungicides, tebconazole was implicated a lead compound for SL biosynthesis inhibitors [22]. Furthermore, though CYPs are not the target proteins, hydroxamic acid derivatives have been also reported as SL biosynthesis inhibitor [23]. However, the studies of SL biosynthesis inhibitor are still underdeveloped. Until now, only three groups of chemicals (TIS13, tebuconazole, and hydroxamic acid derivatives) have been found to be SL biosynthesis inhibitors (Supplementary Material Figure S1).

In this study, to find a novel compound which has inhibitory activity against SL biosynthesis, we evaluated the effects of several heterocyclic nitrogen-containing compounds on SL biosynthesis. The results showed that triflumizole is a novel lead compound for SL biosynthesis inhibition in rice.

\section{Results}

\subsection{Screening for Compounds that Decrease $4 D O$ Levels in Rice Root Exudates}

To screen for compounds that inhibit SL biosynthesis in rice seedlings, the effects of 27 P450 inhibitors were evaluated, which are commercially available, as they are used as agrochemicals (Supplementary Material Figure S2). The inhibition of SL biosynthesis was determined by measuring the level of $4 \mathrm{DO}$, a major endogenous SL in rice, in rice root exudates by liquid chromatography-tandem mass spectrometry (LC-MS/MS). It is known that the endogenous level of $4 \mathrm{DO}$ in roots correlates with that in root exudates [20]. To allow easy detection of $4 \mathrm{DO}$ by LC-MS/MS, rice seedlings were grown under phosphate-deficient conditions [3,24]. First, the effect of the tested compounds at $1 \mu \mathrm{M}$ on $4 \mathrm{DO}$ levels were measured in root exudates. In comparison with the $4 \mathrm{DO}$ levels in root exudates of untreated rice, 11 compounds displayed statistically significant differences in their 4DO levels (Figure 2A). Diniconazole, triflumizole, and bromuconazole showed comparatively good 4DO inhibitory activity among the tested compounds (Figure 2A) and were selected for further analysis. Next, the reduction of $4 \mathrm{DO}$ levels in root exudates by the three compounds was evaluated at the concentrations of 1 and $10 \mu \mathrm{M}$. All three reduced the levels of $4 \mathrm{DO}$ in a dose-dependent manner. Of the three compounds, triflumizole showed the strongest 4DO inhibitory activity in root exudates (Figure 2B). Triflumizole is a fungicide that acts by inhibiting P450, which catalyzes ergosterol biosynthesis (Figure 2C) [25]. This is the first observation in which triflumizole inhibits SL production. Furthermore, the structure of triflumizole differs markedly from those of other known SL biosynthesis inhibitors. For instance, TIS108 has ketone and triazole moieties, while triflumizole has anil ( $\mathrm{N}$-phenyl imine) and imidazole moieties (Figure 2C). The inhibition of 4DO production in rice root exudates by triflumizole and TIS108, both of which are potent SL biosynthesis inhibitors, was compared (Figure 2D). Rice treated with $1.0 \mu \mathrm{M}$ triflumizole or TIS108 displayed significantly reduced 4DO levels. Although the 4DO levels in $0.1 \mu \mathrm{M}$ triflumizole-treated rice were higher than those in $0.1 \mu \mathrm{M}$ TIS108-treated rice, the reduction rate of the $4 \mathrm{DO}$ levels and the novel chemical structure of triflumizole indicate that the compound could be a good lead compound for development of a potent SL biosynthesis inhibitor.

\subsection{Os900 Inhibition Assay of Tested Compounds}

To determine the effect of the tested compounds at $10 \mu \mathrm{M}$ on Os900, which is a P450 protein in the SL biosynthesis pathway, an Os900 inhibition assay was performed. Since Os900 is involved in the two-step conversion from CL to CLA and CLA to 4DO [13], we used CL as a substrate and measured CLA levels by LC-MS/MS. As reported by Yoneyama et al. [13], microsomal proteins, including Os900 from heterologously expressed yeast were collected and used for the assay. The addition of triflumizole to Os900-containing microsomal proteins produced a significant reduction in CLA levels (Figure 3). Diniconazole and bromuconazole did not affect the CLA levels in the Os900 inhibition assay, although these compounds reduced the $4 \mathrm{DO}$ levels in root exudates. 


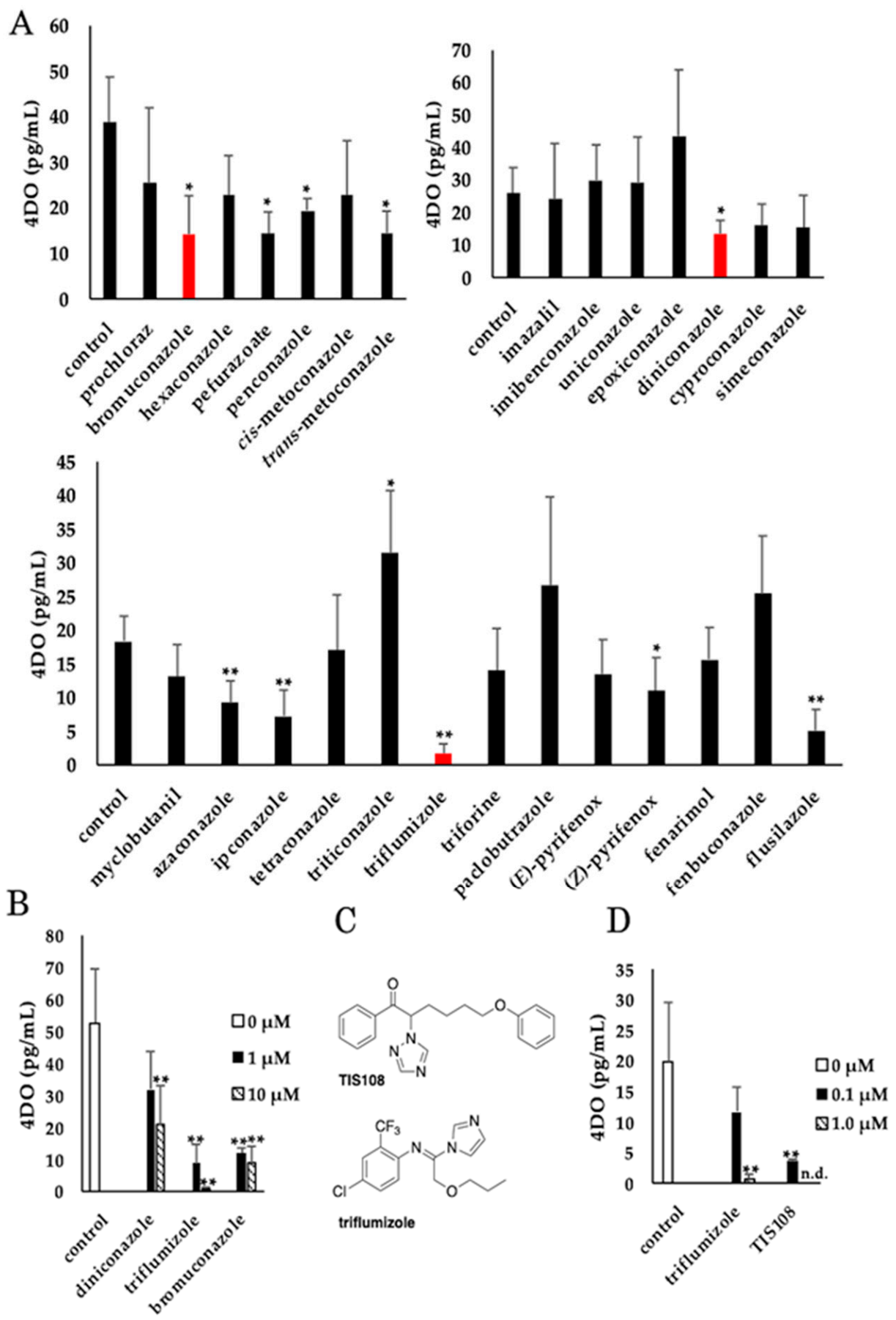

Figure 2. Effects of tested compounds on $4 \mathrm{DO}$ levels in rice root exudates. The levels of $4 \mathrm{DO}$ in rice root exudates treated with (A) $1 \mu \mathrm{M}$ and (B) 1 or $10 \mu \mathrm{M}$ of the screened compounds determined by LC-MS/MS. (A) Red bars represent the compounds which showed the lowest 4DO level in each experiment. (B) White, black, and slash bars are represented as the application of the 0,1 , and $10 \mu \mathrm{M}$ compounds, respectively. (C) The chemical structures of TIS108 and triflumizole. (D) Comparison of the effect of 0.1 and $1 \mu \mathrm{M}$ TIS108 and triflumizole on 4DO levels in the exudate of rice roots. White, black, and slash bars are represented as the application of the $0,0.1$, and $1 \mu \mathrm{M}$ compounds, respectively. n.d.: not detected. The data are mean $\pm \mathrm{SD}(n=3$ in panels $\mathrm{A}$ and $\mathrm{B}, n=5$ in panel D). * and ${ }^{* *}$ denote statistically significant difference from the level in control plants ( $t$ test; $p<0.05$ and $p<0.01$, respectively). 


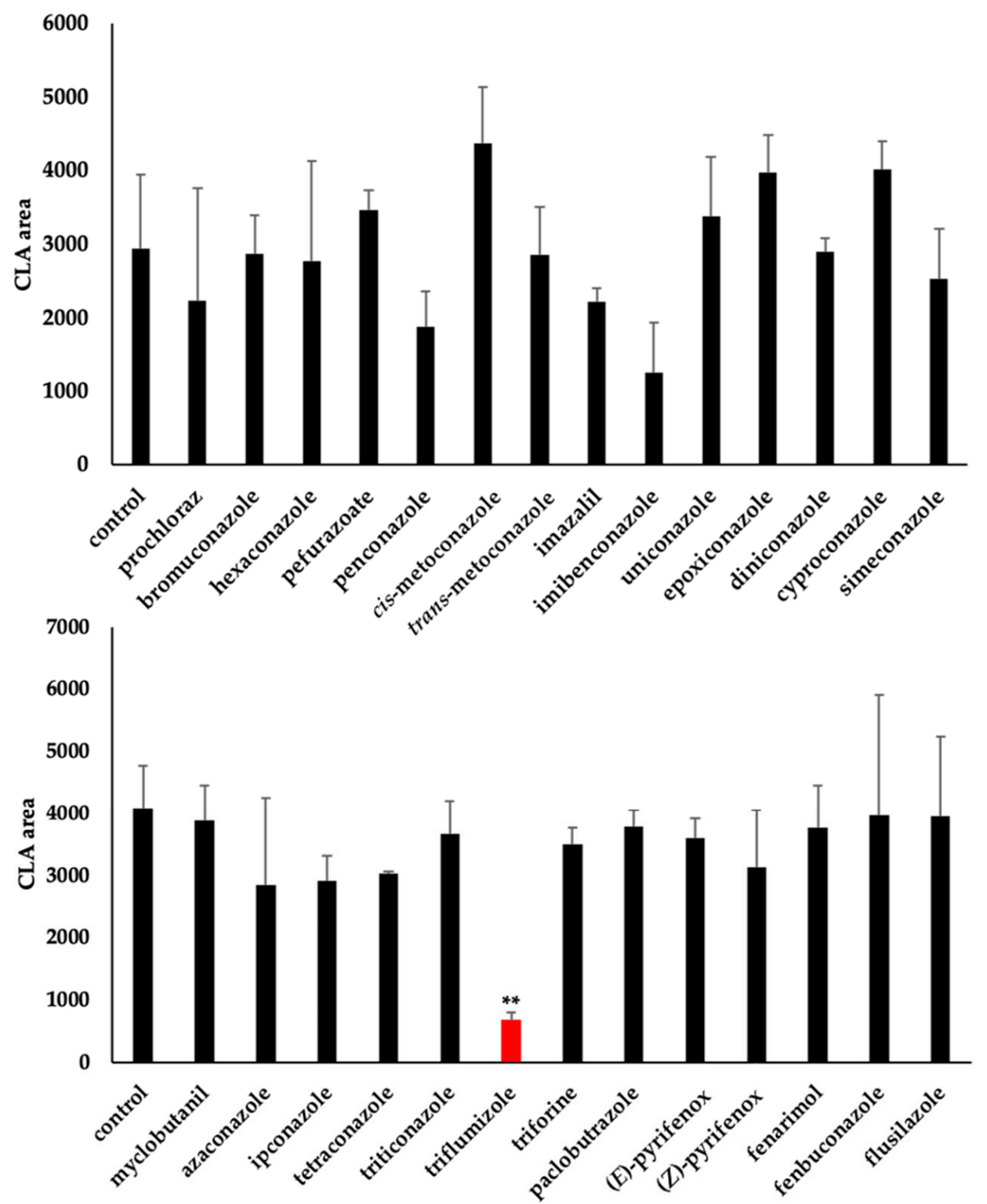

Figure 3. Effect of screening compounds on Os900 in vitro. CLA levels following the addition of $10 \mu \mathrm{M}$ of each compound to microsomal proteins, including Os900. CLA levels were determined by LC-MS/MS. Red bar represents the compound which showed the lowest CLA area. The data are presented as mean $\pm \operatorname{SD}(n=3)$. ${ }^{* *}$ denotes statistically significant difference from the CLA level in the no-application of chemicals (control) $(t$ test; $p<0.01)$.

\subsection{Effect of Triflumizole on SL Biosynthesis}

Of the test compounds, triflumizole treatment reduced 4DO levels most effectively in rice root exudates. In addition, triflumizole inhibited Os900 activity in vitro. Therefore, we selected triflumizole as a candidate for a novel lead compound of an SL biosynthesis inhibitor in rice and performed further experiments.

To confirm that triflumizole regulates SL biosynthesis by inhibiting Os900 activity in vitro, the Os900 inhibition assay was performed using various concentrations of triflumizole. The conversion of CL to CLA and CL to 4DO was determined (Figure 4A,B). The addition of 10-100 $\mu \mathrm{M}$ triflumizole to Os900-containing microsomal proteins reduced the levels of both products in a dose-dependent manner (Figure $4 \mathrm{~A}, \mathrm{~B}$ ). This pattern of reduction indicated that one of the target enzymes of triflumizole could be Os900. To confirm that triflumizole actually inhibits SL biosynthesis in vivo, we analyzed the 
endogenous levels of 4DO in rice roots and root exudates (Figure 4C,D). The 4DO levels in both root exudates of rice treated with triflumizole were reduced in a dose-dependent manner at concentrations ranging from 1-10 $\mu \mathrm{M}$. These results suggested that triflumizole inhibits SL biosynthesis in vitro and in vivo.

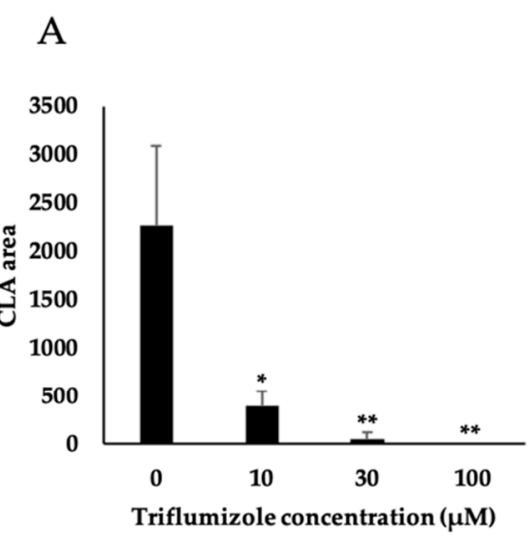

C

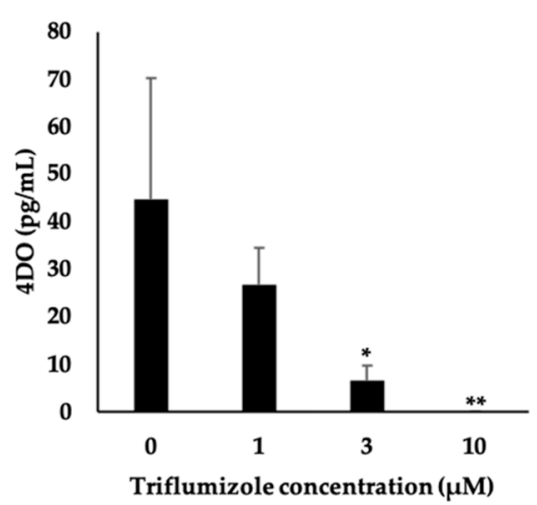

B

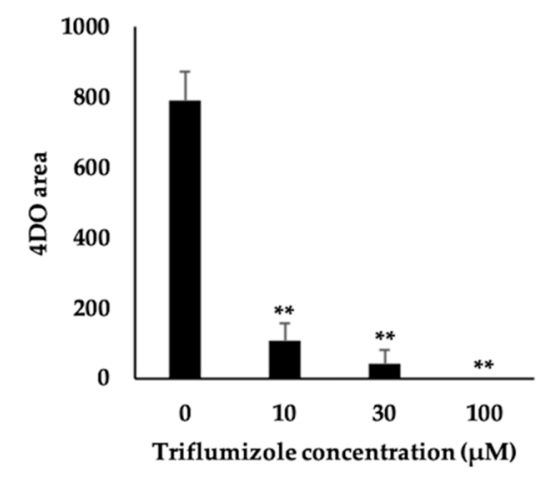

D

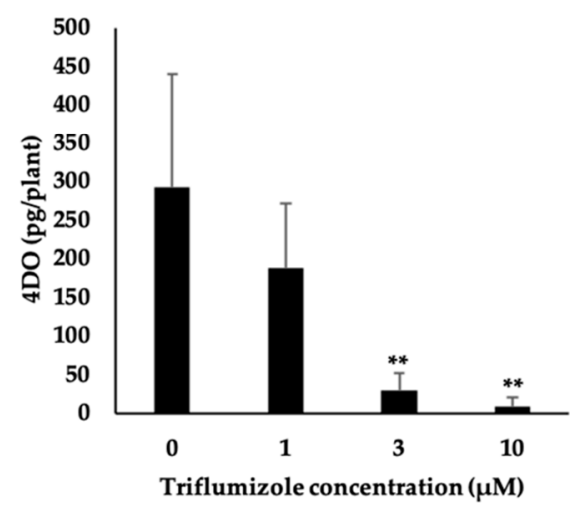

Figure 4. Effect of triflumizole on rice SL biosynthesis. Effect of triflumizole addition to Os900 expressed yeast microsomal protein on the levels of CLA (A) and 4DO (B) as determined by LC-MS/MS. The data are mean $\pm \mathrm{SD}(n=3)$. Statistical difference from the CLA (A) or $4 \mathrm{DO}(\mathbf{B})$ level of the $0 \mu \mathrm{M}$ triflumizole is indicated by * $(t$ test; $0.01<p<0.05)$ and ${ }^{* *}$ ( $t$ test; $\left.p<0.01\right)$. Effect of triflumizole addition to rice on $4 \mathrm{DO}$ levels in rice root exudates $(\mathbf{C})$ and roots $(\mathbf{D})$. The data are means $\pm \operatorname{SD}(n=5)$. Statistically different from the $4 \mathrm{DO}$ level of the control plants $\left(\left(^{*}\right)=t\right.$ test; $0.01<p<0.05,\left({ }^{* *}\right)=t$ test; $\left.p<0.01\right)$.

\subsection{Side Effect of Triflumizole}

P450 inhibitors containing triazole and imidazole groups often induce dwarfism in rice because of the presence of various types of P450s in the gibberellin and brassinosteroid biosynthesis pathways. TIS13 induces a severe dwarf phenotype to rice as a side effect, which is rescued by the addition of gibberellin to rice [19]. Triadimefon is a fungicidal triazole-type P450 inhibitor but inhibits gibberellin and brassinosteroid biosynthesis [26]. Based on these results, we examined the side effects of triflumizole by measuring the height of rice plants from the ground to the highest leaf treated with triflumizole. Triflumizole treatment slightly but significantly reduced plant height in a dose-dependent manner (Figure 5). TIS108 and KK5 do not reduce the height of rice plants when applied at $50 \mu \mathrm{M}$ [21]. The collective findings indicate that triflumizole seems to inhibit the enzymatic activity of Os900 as well as the activities of other $\mathrm{P} 450$ proteins in the gibberellin and/or brassinosteroid biosynthesis pathways. 


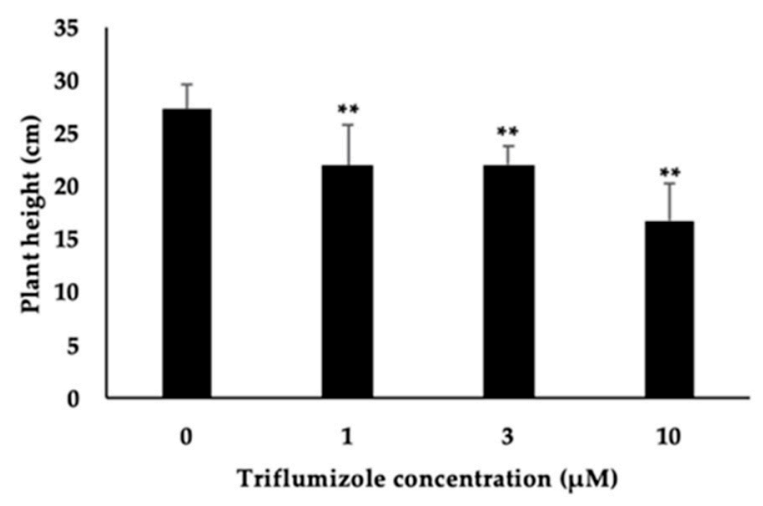

Figure 5. Plant height of 23-day-old rice seedling supplemented with 1, 3, or $10 \mu \mathrm{M}$ triflumizole for two weeks. The data are expressed as mean $\pm \operatorname{SD}(n=10)$. ${ }^{* *}$ denotes statistically significant difference from the plant height of non-treated triflumizole ( $t$ test; $p<0.01)$.

\subsection{Striga Germination Assay}

Root parasitic plants, such as Striga and Orobanche, sense SLs, which induces germination. Hence, the lower levels of SLs in triflumizole-treated rice could reduce Striga germination. We checked the effects of treating rice seedlings with triflumizole on $S$. hermonthica germination. The root exudates of triflumizole-treated rice significantly reduced Striga germination in a dose-dependent manner (Figure 6). In addition, the co-application of triflumizole with GR24 (synthetic SL analog) induced Striga germination (Supplementary Material Figure S3), suggesting that the reduction of Striga germination treated with the root exudates of triflumizole-treated rice is not caused by the direct inhibition of Striga germination. These results corresponded with the results of the 4DO analysis in root exudates and roots, and indicated that triflumizole could control the germination of root parasitic plants dependent on SLs as a germination trigger.

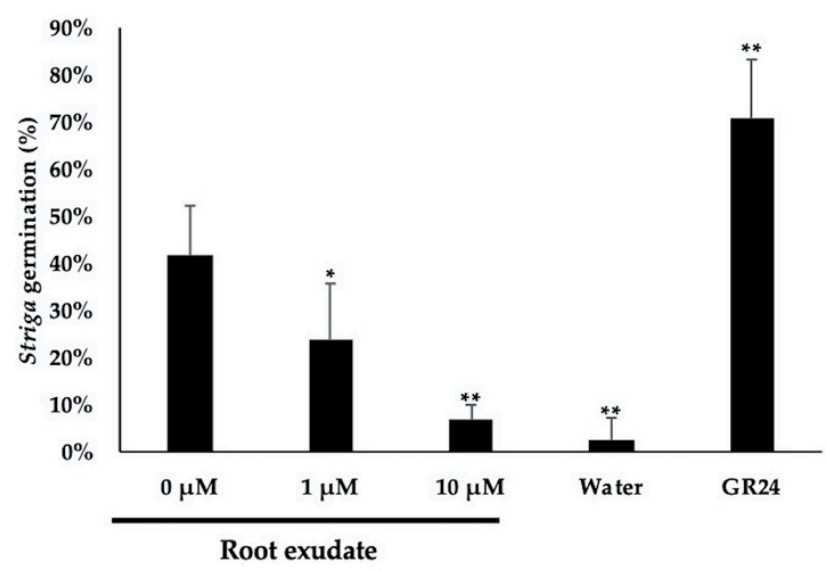

Figure 6. Germination of Striga seeds in the culture media of root exudates from untreated rice $(0 \mu \mathrm{M}$ triflumizole) and rice treated with 1 and $10 \mu \mathrm{M}$ triflumizole. GR24 (synthetic SL analog) and sterile water were used as positive and negative controls, respectively. The data are expressed as mean \pm SD of five samples. Statistically different from the germination percentage of $0 \mu \mathrm{M}$ triflumizole $\left(\left(^{*}\right)=t\right.$ test; $0.01<p<0.05,(* *)=t$ test; $p<0.01)$.

\section{Discussion}

To identify novel lead compounds as SL biosynthesis inhibitors, we evaluated 27 P450 inhibitors known to be fungicides and plant growth retardants. Three compounds significantly reduced the 4DO levels in the root exudates of rice when applied at $1 \mu \mathrm{M}$. In particular, triflumizole reduced the levels of $4 \mathrm{DO}$ in rice roots and root exudates at concentrations ranging from $0.1-10 \mu \mathrm{M}$. Hydroxamic acid 
and TIS108 derivatives have been identified as inhibitors of SL biosynthesis. However, the activity of anil compounds, such as triflumizole, has not been reported. We observed that triflumizole treatment inhibited the Os900-mediated of CL to CLA and 4DO. These results indicate that Os900 is a target protein of triflumizole and that the inhibition of Os900 activity by triflumizole leads to the reduction of 4DO levels in roots and root exudates of rice. However, it is unclear whether triflumizole inhibits the activity of other CYP711As, including Os1400 and AtMAX1. To know the target enzymes of triflumizole in detail, we intend to assess the effects of triflumizole on other CYP711As by the inhibition assay of those enzymes in the near future. Interestingly, treatment with $10 \mu \mathrm{M}$ bromuconazole and diniconazole reduced 4DO levels in rice exudates by half of the levels in control rice, although these compounds did not inhibit the enzymatic activity of Os900. The D27 and CCD families consist of iron-containing proteins [27-30]. Iron ions at the active site of CCD proteins are chelated by four histidine residues [31]. It is possible that the heterocyclic nitrogen-containing compounds, such as imidazole and triazole, chelate iron and inhibit CCD proteins. Considering the collective results, it is plausible that bromuconazole and diniconazole inhibit SL biosynthesis by inhibiting the activities of the D27, CCD7, or CCD8 enzymes involved in SL biosynthesis. Plants harbor various P450s involved in plant hormone biosynthesis and metabolism. These hormones include gibberellin, brassinosteroid, and abscisic acid [32-35], suggesting the possibility that triflumizole inhibits these P450s. Gibberellin- or brassinosteroid-deficient mutants cause dwarfism in rice and display the dwarf phenotype. Paclobutrazol, which is a gibberellin biosynthesis inhibitor, produces the gibberellin deficient mutant-like phenotype [36-38]. It was observed that 23-day-old rice plants treated with triflumizole for 2 weeks showed the dwarf phenotype, suggesting that triflumizole inhibits the CYP711A family as well as other P450s, including those involved in gibberellin and brassinosteroid biosynthesis.

In this study, it was found that triflumizole inhibits SL biosynthesis in rice by inhibiting Os 900 activity. As SLs play an important role in plant development and resistance of environmental stress $[1,39]$, triflumizole may be useful tool for analyzing the influence of SL biosynthesis inhibition and controlling the damage of root parasitic plants. However, because the dwarf phenotype is a side effect of triflumizole, a structure-activity relationship study using triflumizole as the lead compound will be necessary in the near future to attempt to reduce this side effect and conclusively establish triflumizole derivatives as a specific SL biosynthesis inhibitor.

\section{Materials and Methods}

\subsection{Rice Growth Condition}

The Nipponbare normal species was used as the wild-type rice. Rice seeds were grown as described in a previous study [3]. Rice seeds were sterilized by $2.5 \%$ sodium hypochlorite, added to sterile water, and incubated at $25^{\circ} \mathrm{C}$ in the dark for $2 \mathrm{~d}$. The germinated seeds were transferred into a phosphate-deficient hydroponic culture medium adjusted to $\mathrm{pH} 5.7\left(1 \mathrm{mM} \mathrm{NH} \mathrm{NO}_{3}, 0.3 \mathrm{mM} \mathrm{K}_{2} \mathrm{CO}_{3}\right.$, $0.4 \mathrm{mM} \mathrm{MgCl}_{2}, 0.2 \mathrm{mM} \mathrm{CaCl}_{2}, 45 \mu \mathrm{M}$ Fe-EDTA, $50 \mu \mathrm{M} \mathrm{H}_{3} \mathrm{BO}_{3}, 9 \mu \mathrm{M} \mathrm{MnSO}_{4}, 0.3 \mu \mathrm{M} \mathrm{CuSO}_{4}, 0.7 \mu \mathrm{M}$ $\mathrm{ZnSO}_{4}$, and $0.1 \mu \mathrm{M} \mathrm{Na}_{2} \mathrm{MoO}_{4}$ ), solidified with $0.7 \%$ agar, and cultivated at $25^{\circ} \mathrm{C}$ under fluorescent white light with a 14-h light and 10-h dark photoperiod for $7 \mathrm{~d}$. Each seedling was transferred to a brown vial with $12 \mathrm{~mL}$ of phosphate-deficient medium and incubated under the same conditions for $6 \mathrm{~d}$. After that, these seedlings were transferred to a new brown vial containing $12 \mathrm{~mL}$ of the same media supplemented with the tested compounds and grown under the same conditions for $1 \mathrm{~d}$. All tested compounds were purchased from FUJIFILM Wako Pure Chemical Corporation (Osaka, Japan). To measure the 4DO levels and the Striga germination percentage, hydroponic culture media and roots were collected. 4DO levels were measured in three (Figure 2A,B) or five (Figures 2D and 4C,D) biological replicates. To assess plant growth, the germinated seeds were transferred into a hydroponic culture medium, containing $0.6 \mathrm{mM} \mathrm{Na}_{2} \mathrm{HPO}_{4}$ solidified with $0.7 \%$ agar and cultivated at the same condition as previously described [3]. 9-day-old seedings were transferred to a new brown vial containing $12 \mathrm{~mL}$ of a hydroponic culture media supplemented with triflumizole for two weeks. 
Plant height was measured from the ground to the highest leaf of the plant in 10 biological replicates that were 23 days old [40].

\subsection{Quantification of the Endogenous 4DO Level}

To analyze $4 \mathrm{DO}$ in rice root exudates, the hydroponic culture medium was extracted with ethyl acetate twice after the addition of deuterium-labeled 5-deoxystrigol $\left(\mathrm{d}_{6}-5 \mathrm{DS} ; 400 \mathrm{pg}\right)$ as an internal standard [41]. The organic layer was concentrated in vacuo. To analyze $4 \mathrm{DO}$ in roots, roots were homogenized in acetone with $\mathrm{d}_{6}$-5DS added and filtered the suspension. The filtrates were concentrated and dissolved in 10\% acetone. The solution was loaded onto Oasis HLB 3-mL cartridges (Waters, Milford, MA, USA), washed twice with deionized water ( $3 \mathrm{~mL})$, eluted twice with acetone $(3 \mathrm{~mL})$, concentrated, and dissolved in $1 \mathrm{~mL}$ of $n$-hexane:ethyl acetate (85:15). The solution was loaded on a Sep-Pak silica 1-mL cartridge (Waters), flowed twice with $1 \mathrm{~mL}$ of $n$-hexane:ethyl acetate (85:15), eluted three times with $n$-hexane:ethyl acetate (65:35), and concentrated in vacuo [42].

The concentrates were dissolved in acetonitrile:deionized water (1:1) and subjected to LC-MS/MS analysis performed as reported previously [42].

\subsection{Examination of Inhibition of Os900}

\subsubsection{Conditions of the Enzyme Assay}

Heterologous expression of Os900, collection of microsomal proteins, and the enzymatic reaction were performed as described in a previous study [13]. Rac-CL was synthesized according to a previous study [43].

Rac-CL and Os900 were incubated with NADPH $(50 \mu \mathrm{M})$ in the presence or absence of test compounds at $28^{\circ} \mathrm{C}$ for $40 \mathrm{~min}$. The reaction mixture was quenched with $100 \mu \mathrm{L}$ of ethyl acetate and added $50 \mu \mathrm{L}$ of water. The mixture was extracted with $100 \mu \mathrm{L}$ of ethyl acetate three times. The combined ethyl acetate fractions were concentrated in vacuo. The concentrates were dissolved in acetonitrile and analyzed by LC-MS/MS.

\subsubsection{LC-MS/MS Analysis of CLA Level}

LC-MS/MS analysis was performed with a quadruple/time-of-flight tandem mass spectrometer (TripleTOF5600 system; SCIEX, Framingham, MA, USA) and an ultrahigh-performance liquid chromatograph (Nexera; Shimadzu, Kyoto, Japan) provided with a reversed-phase column (Acquity UPLC BEH-C18, $2.1 \times 50 \mathrm{~mm}, 1.7 \mu \mathrm{m}$; Waters).

In the separation by ultrahigh-performance liquid chromatography, we used water (solvent A) and acetonitrile (solvent $\mathrm{B}$ ), which both contained $0.1 \%(v / v)$ formic acid. The mobile phase had a flow rate of $0.2 \mathrm{~mL} / \mathrm{min}$ and was altered with linear gradient of 20 to $60 \%$ solvent $\mathrm{B}(0-2 \mathrm{~min}), 60$ to $100 \%$ solvent B (2-9 $\mathrm{min})$, and 100 to $20 \%$ solvent B (12-12.10 min). The parent ions $(\mathrm{m} / \mathrm{z})$ were 331.2 for CLA. The samples were quantified using fragment ions 113.1 for CLA in the negative mode.

\subsection{Striga Assay}

The Striga germination assay was performed as previously described [44]. Striga hermonthica seeds were sterilized with $1 \%$ sodium hypochlorite solution containing Tween-20 for 5 min and washed five times with sterile water. The seeds were then suspended in $1 \%$ agar solution and loaded on $5-\mathrm{mm}$ glass fiber filter paper disks (20-60 seeds/disk). After incubation at $30^{\circ} \mathrm{C}$ for 7 days, each disk was transferred into a well of a 48 or 96 well plate. Each well was added with $20 \mu \mathrm{L}$ of the extract of hydroponic culture media dissolved in $500 \mu \mathrm{L}$ of sterile water. GR2 $4(0.1 \mu \mathrm{M})$ was used as a positive control and sterile water as a negative control. The 48 or 96 well plates were incubated for 1 or 2 days at $30^{\circ} \mathrm{C}$; then, the percentage of germination was recorded. Each experiment was performed in five biological replicates. 
Supplementary Materials: The following are available online. Figure S1: Three groups of chemicals known as Strigolactone biosynthesis inhibitor, Figure S2: Structure of tested compounds used for screening, Figure S3: Effect of triflumizole on Striga germination rate, Figure S4: Pictures of Striga gemination.

Author Contributions: Screening of tested compounds, Y.U. and K.K.; LC-MS/MS analysis, S.I. and K.K.; Os900 expression and enzyme assay, K.K. and T.N.; Striga germination assay, K.K. and I.T.; Experimental design, T.N., Y.S., T.A., S.Y., and S.I.; Writing the manuscript, K.K. and S.I. All authors have read and agreed to the published version of the manuscript.

Funding: The study was supported, in part, by a grant from the Japan Society for the Promotion of Science (JSPS) Grant-in-Aid for Scientific Research to T.A. (S; Grant 18H05266), and from Tokyo University of Agriculture to S.I.

Acknowledgments: The authors are obliged to A.G. Babiker for kindly providing the Striga seed.

Conflicts of Interest: The authors declare no conflict of interest in this study.

\section{References}

1. Omoarelojie, L.O.; Kulkarni, M.G.; Finnie, J.F.; Van Staden, J. Strigolactones and their crosstalk with other phytohormones. Ann. Bot. 2019, 124, 749-767. [CrossRef] [PubMed]

2. Gomez-Roldan, V.; Fermas, S.; Brewer, P.B.; Puech-Pagès, V.; Dun, E.A.; Pillot, J.P.; Letisse, F.; Matusova, R.; Danoun, S.; Portais, J.C.; et al. Strigolactone inhibition of shoot branching. Nature 2008, 455, 189-194. [CrossRef] [PubMed]

3. Umehara, M.; Hanada, A.; Yoshida, S.; Akiyama, K.; Arite, T.; Takeda-Kamiya, N.; Magome, H.; Kamiya, Y.; Shirasu, K.; Yoneyama, K.; et al. Inhibition of shoot branching by new terpenoid plant hormones. Nature 2008, 455, 195-200. [CrossRef]

4. Lopez-Obando, M.; Ligerot, Y.; Bonhomme, S.; Boyer, F.D.; Rameau, C. Strigolactone biosynthesis and signaling in plant development. Development 2015, 142, 3615-3619. [CrossRef] [PubMed]

5. Akiyama, K.; Matsuzaki, K.; Hayashi, H. Plant sesquiterpenes induce hyphal branching in arbuscular mycorrhizal fungi. Nature 2005, 435, 824-827. [CrossRef]

6. Cook, C.E.; Whichard, L.P.; Turner, B.; Wall, M.E.; Egley, G.H. Germination of Witchweed (Striga lutea Lour.): Isolation and Properties of a Potent Stimulant. Science 1966, 154, 1189-1190. [CrossRef]

7. Spallek, T.; Mutuku, M.; Shirasu, K. The genus Striga: A witch profile. Mol. Plant. Pathol. 2013, 14, 861-869. [CrossRef]

8. Ejeta, D. Breeding for Resistance in Sorghum: Exploitation of an Intricate Host-Parasite Biology. Crop. Sci. 2007, 47, S216-S227. [CrossRef]

9. Rademacher, W. Plant Growth Regulators: Backgrounds and Uses in Plant Production. J. Plant Growth Regul. 2015, 34, 845-872. [CrossRef]

10. Alder, A.; Jamil, M.; Marzorati, M.; Bruno, M.; Vermathen, M.; Bigler, P.; Ghisla, S.; Bouwmeester, H.; Beyer, P.; Al-Babili, S. The path from $\beta$-carotene to carlactone, a strigolactone-like plant hormone. Science 2012, 335, 1348-1351. [CrossRef]

11. Booker, J.; Auldridge, M.; Wills, S.; McCarty, D.; Klee, H.; Leyser, O. MAX3/CCD7 is a carotenoid cleavage dioxygenase required for the synthesis of a novel plant signaling molecule. Curr. Biol. 2004, 14, 1232-1238. [CrossRef] [PubMed]

12. Abe, S.; Sado, A.; Tanaka, K.; Kisugi, T.; Asami, K.; Ota, S.; Kim, H.I.; Yoneyama, K.; Xie, X.; Ohnishi, T.; et al. Carlactone is converted to carlactonoic acid by MAX1 in Arabidopsis and its methyl ester can directly interact with AtD14 in vitro. Proc. Natl. Acad. Sci. USA 2014, 111, 18084-18089. [CrossRef] [PubMed]

13. Yoneyama, K.; Mori, N.; Sato, T.; Yoda, A.; Xie, X.; Okamoto, M.; Iwanaga, M.; Ohnishi, T.; Nishiwaki, H.; Asami, T.; et al. Conversion of carlactone to carlactonoic acid is a conserved function of MAX1 homologs in strigolactone biosynthesis. New Phytol. 2018, 218, 1522-1533. [CrossRef] [PubMed]

14. Neunzig, I.; Drăgan, C.A.; Widjaja, M.; Schwaninger, A.E.; Peters, F.T.; Maurer, H.H.; Bureik, M. Whole-cell biotransformation assay for investigation of the human drug metabolizing enzyme CYP3A7. Biochim. Biophys. Acta 2011, 1814, 161-167. [CrossRef] [PubMed]

15. Zhang, Z.; Gao, B.; He, Z.; Li, L.; Zhang, Q.; Kaziem, A.E.; Wang, M. Stereoselective bioactivity of the chiral triazole fungicide prothioconazole and its metabolite. Pestic. Biochem. Physiol. 2019, 160, 112-118. [CrossRef]

16. Min, Y.K.; Asami, T.; Fujioka, S.; Murofushi, N.; Yamaguchi, I.; Yoshida, S. New lead compounds for brassinosteroid biosynthesis inhibitors. Bioorg. Med. Chem. Lett. 1999, 9, 425-430. [CrossRef] 
17. Sasaki, E.; Ogura, T.; Takei, K.; Kojima, M.; Kitahata, N.; Sakakibara, H.; Asami, T.; Shimada, Y. Uniconazole, a cytochrome P450 inhibitor, inhibits trans-zeatin biosynthesis in Arabidopsis. Phytochemistry 2013, 87, 30-38. [CrossRef]

18. Takeuchi, J.; Okamoto, M.; Mega, R.; Kanno, Y.; Ohnishi, T.; Seo, M.; Todoroki, Y. Abscinazole-E3M, a practical inhibitor of abscisic acid 8'-hydroxylase for improving drought tolerance. Sci. Rep. 2016, 6, 37060. [CrossRef]

19. Ito, S.; Kitahata, N.; Umehara, M.; Hanada, A.; Kato, A.; Ueno, K.; Mashiguchi, K.; Kyozuka, J.; Yoneyama, K.; Yamaguchi, S.; et al. A new lead chemical for strigolactone biosynthesis inhibitors. Plant. Cell. Physiol. 2010, 51, 1143-1150. [CrossRef]

20. Ito, S.; Umehara, M.; Hanada, A.; Kitahata, N.; Hayase, H.; Yamaguchi, S.; Asami, T. Effects of triazole derivatives on strigolactone levels and growth retardation in rice. PLoS ONE 2011, 6, e21723. [CrossRef]

21. Kawada, K.; Takahashi, I.; Arai, M.; Sasaki, Y.; Asami, T.; Yajima, S.; Ito, S. Synthesis and Biological Evaluation of Novel Triazole Derivatives as Strigolactone Biosynthesis Inhibitors. J. Agric. Food Chem. 2019, 67, 6143-6149. [CrossRef] [PubMed]

22. Ito, S.; Umehara, M.; Hanada, A.; Yamaguchi, S.; Asami, T. Tebuconazole derivatives are potent inhibitors of strigolactone biosynthesis. J. Pestic. Sci. 2013, 38, 147-151. [CrossRef]

23. Harrison, P.J.; Newgas, S.A.; Descombes, F.; Shepherd, S.A.; Thompson, A.J.; Bugg, T.D. Biochemical characterization and selective inhibition of $\beta$-carotene cis-trans isomerase D27 and carotenoid cleavage dioxygenase CCD8 on the strigolactone biosynthetic pathway. FEBS J. 2015, 282, 3986-4000. [CrossRef] [PubMed]

24. Yoneyama, K.; Xie, X.; Kusumoto, D.; Sekimoto, H.; Sugimoto, Y.; Takeuchi, Y. Nitrogen deficiency as well as phosphorus deficiency in sorghum promotes the production and exudation of 5-deoxystrigol, the host recognition signal for arbuscular mycorrhizal fungi and root parasites. Planta 2007, 227, 125-132. [CrossRef] [PubMed]

25. Nakayama, A.; Ikura, K.; Katsuura, K.; Hashimoto, S.; Nakata, A. Quantitative Structure-Activity Relationships, Conformational Analyses and Computer Graphics Study of Triflumizole Analogs, Fungicidal N-(1-Imidazol-1-ylalkylidene)anilines. J. Pestic. Sci. 1989, 14, 23-37. [CrossRef]

26. Asami, T.; Mizutani, M.; Shimada, Y.; Goda, H.; Kitahata, N.; Sekimata, K.; Han, S.Y.; Fujioka, S.; Takatsuto, S.; Sakata, K.; et al. Triadimefon, a fungicidal triazole-type P450 inhibitor, induces brassinosteroid deficiency-like phenotypes in plants and binds to DWF4 protein in the brassinosteroid biosynthesis pathway. Biochem. J. 2003, 369, 71-76. [CrossRef]

27. Lin, H.; Wang, R.; Qian, Q.; Yan, M.; Meng, X.; Fu, Z.; Yan, C.; Jiang, B.; Su, Z.; Li, J.; et al. DWARF27, an iron-containing protein required for the biosynthesis of strigolactones, regulates rice tiller bud outgrowth. Plant Cell 2009, 21, 1512-1525. [CrossRef]

28. Kloer, D.P.; Ruch, S.; Al-Babili, S.; Beyer, P.; Schulz, G.E. The structure of a retinal-forming carotenoid oxygenase. Science 2005, 308, 267-269. [CrossRef]

29. Kloer, D.P.; Schulz, G.E. Structural and biological aspects of carotenoid cleavage. Cell. Mol. Life Sci. 2006, 63, 2291-2303. [CrossRef]

30. Cui, H.; Wang, Y.; Qin, S. Genomewide analysis of carotenoid cleavage dioxygenases in unicellular and filamentous cyanobacteria. Comp. Funct. Genom. 2012, 2012, 164690. [CrossRef]

31. Harrison, P.J.; Bugg, T.D. Enzymology of the carotenoid cleavage dioxygenases: Reaction mechanisms, inhibition and biochemical roles. Arch. Biochem. Biophys. 2014, 544, 105-111. [CrossRef] [PubMed]

32. Helliwell, C.A.; Sheldon, C.C.; Olive, M.R.; Walker, A.R.; Zeevaart, J.A.; Peacock, W.J.; Dennis, E.S. Cloning of the Arabidopsis ent-kaurene oxidase gene GA3. Proc. Natl. Acad. Sci. USA 1998, 95, 9019-9024. [CrossRef] [PubMed]

33. Helliwell, C.A.; Chandler, P.M.; Poole, A.; Dennis, E.S.; Peacock, W.J. The CYP88A cytochrome P450, ent-kaurenoic acid oxidase, catalyzes three steps of the gibberellin biosynthesis pathway. Proc. Natl. Acad. Sci. USA 2001, 98, 2065-2070. [CrossRef] [PubMed]

34. Sakurai, A.; Fujioka, S. Studies on biosynthesis of brassinosteroids. Biosci. Biotechnol. Biochem. 1997, 61, 757-762.

35. Saito, S.; Hirai, N.; Matsumoto, C.; Ohigashi, H.; Ohta, D.; Sakata, K.; Mizutani, M. Arabidopsis CYP707As encode (+)-abscisic acid 8'-hydroxylase, a key enzyme in the oxidative catabolism of abscisic acid. Plant Physiol. 2004, 134, 1439-1449. [CrossRef] 
36. Schomburg, F.M.; Bizzell, C.M.; Lee, D.J.; Zeevaart, J.A.; Amasino, R.M. Overexpression of a novel class of gibberellin 2-oxidases decreases gibberellin levels and creates dwarf plants. Plant Cell 2003, 15, 151-163. [CrossRef]

37. Lo, S.F.; Yang, S.Y.; Chen, K.T.; Hsing, Y.I.; Zeevaart, J.A.; Chen, L.J.; Yu, S.M. A novel class of gibberellin 2-oxidases control semidwarfism, tillering, and root development in rice. Plant Cell 2008, 20, 2603-2618. [CrossRef]

38. Zhang, A.; Xie, X.; Liu, W. Enantioselective separation and phytotoxicity on rice seedlings of paclobutrazol. J. Agric. Food Chem. 2011, 59, 4300-4305. [CrossRef]

39. Li, W.; Nguyen, K.H.; Tran, C.D.; Watanabe, Y.; Tian, C.; Yin, X.; Li, K.; Yang, Y.; Guo, J.; Miao, Y.; et al. Negative Roles of Strigolactone-Related SMXL6, 7 and 8 Proteins in Drought Resistance in Arabidopsis. Biomolecules 2020, 10, 607. [CrossRef]

40. Ito, S.; Yamagami, D.; Asami, T. Effects of gibberellin and strigolactone on rice tiller bud growth. J. Pestic. Sci. 2018, 43, 220-223. [CrossRef]

41. Ueno, K.; Hanada, A.; Yamaguchi, S.; Asami, T. Preparation of multideuterated 5-deoxystrigol for use as an internal standard for quantitative LC/MS. J. Label. Compd. Radiopharm. 2010, 53, 763-766. [CrossRef]

42. Ito, S.; Yamagami, D.; Umehara, M.; Hanada, A.; Yoshida, S.; Sasaki, Y.; Yajima, S.; Kyozuka, J.; Ueguchi-Tanaka, M.; Matsuoka, M.; et al. Regulation of Strigolactone Biosynthesis by Gibberellin Signaling. Plant Physiol. 2017, 174, 1250-1259. [CrossRef] [PubMed]

43. Seto, Y.; Sado, A.; Asami, K.; Hanada, A.; Umehara, M.; Akiyama, K.; Yamaguchi, S. Carlactone is an endogenous biosynthetic precursor for strigolactones. Proc. Natl. Acad. Sci. USA 2014, 111, 1640-1645. [CrossRef] [PubMed]

44. Sugimoto, Y.; Ueyama, T. Production of (+)-5-deoxystrigol by Lotus japonicus root culture. Phytochemistry 2008, 69, 212-217. [CrossRef]

Sample Availability: All tested compounds were purchased from FUJIFILM Wako Pure Chemical Corporation (Osaka, Japan).

Publisher's Note: MDPI stays neutral with regard to jurisdictional claims in published maps and institutional affiliations.

(C) 2020 by the authors. Licensee MDPI, Basel, Switzerland. This article is an open access article distributed under the terms and conditions of the Creative Commons Attribution (CC BY) license (http://creativecommons.org/licenses/by/4.0/). 